\title{
Tıp Fakültesi Öğrencilerinde Kraniyofasiyal Antropometrik Ölçümlerin Cinsiyete Bağlı Karşılaştırmalı İncelenmesi
}

* Sorumlu Yazar / Corresponding Author: Tufan ULCAY Kırşehir Ahi Evran Üniversitesi Tıp Fakültesi, Temel Tıp Bilimleri Bölümü Anatomi Anabilim Dalı Bağbaşı Yerleşkesi, Merkez / KIRŞEHIR E-posta: tufanulcay@gmail.com

\section{Tufan Ulcay ${ }^{1 *} \odot$, Burcu Kamaşak ${ }^{2} \odot$}

'Dr. Öğr. Üyesi | Kırşehir Ahi Evran Üniversitesi, Tıp Fakültesi, Anatomi Anabilim Dalı, Kırşehir / TÜRKiYE

${ }^{2}$ Arş. Gör. | Kırşehir Ahi Evran Üniversitesi, Tıp Fakültesi, Anatomi Anabilim Dalı, Kırşehir / TÜRKiYE

Alındı/Received: 2 Mayıs / May 2020

Düzeltildi/Revised: 8 Haziran / June 2020

Kabul/Accepted: 10 Haziran / June 2020

Yayımlandı/Published: 29 Haziran / June 2020

\section{$\ddot{\mathrm{O} z}$}

Yllardan beri insan vücudunun anatomik yapıs1, normal sinırlar ve bunlarla ilgili standart ölçülerin ne olması gerektiği tartışılmış ve birbirleriyle olan ilişkileri incelenerek belirli normlar oluşturulmuştur. Kraniofasiyal antropometri, antropometrinin bir dalı olup canlı, kadavra ve radyolojik örneklerdeki baş ve yüz ölçümlerini kapsamaktadır. Çalışmamızda, Kırșehir Ahi Evran Üniversitesi Tip Fakültesi 1 ve 2. sınıf öğrencilerinin kraniyal ve fasiyal antropometrik ölçümleri ile ulusal normal değerleri belirlemeyi ve cinsiyetler arasındaki olası farklılıkları araştırmayı amaçladık. Bu doğrultuda çalışmamız, yaşları 18 ile 24 arasında değişmekte olan, kraniofasiyal anomalisi olmayan, toplam 80 tıp fakültesi öğrencisi üzerinde yapılmıştır. Öğrencilerin vücut kütle indeksi (BMI) hesaplanmış ve ölçümler için 19 antropometrik nokta belirlenmiştir Baş, yüz, burun ve kulak ile ilgili ölçümlerden; maksimum baş genişliği, kraniyal taban genişliği, maksimum baş uzunluğu, maksimum yüz genişliği, burun genişliği, kulak uzunluğu ve kulak genişliği değişkenleri kız ve erkek grupları arasında istatistiksel olarak anlamlı fark bulunmuştur $(p<0,05)$. Minimum frontal genişlik, baş yüksekliği, total kraniofasiyal baş yüksekliği, mandibular genişlik ve burun yüksekliği değişkenleri kız ve erkek grupları arasında istatistiksel olarak yüksek derecede anlaml fark bulunmuştur $(\mathrm{p}<0,001)$. Normal dağılım göstermeyen BMI değerleri kizlarda 21,4 (19,7-24,0), erkeklerde ise 23,5 (22,1-24,9) olarak hesaplanmıştır. Çalışmamızın sonucunda baş ve yüze ait verilerimiz cinsiyete bağlı olarak anlamlı farklılıklar göstermektedir.

Anahtar Sözcükler: Antropometri, kraniyofasiyal ölçümler, vücut kütle indeksi, baş ve yüz ölçümleri

\section{Giriş}

Antropometri, insan vücudunun bileşiminin, orantılarının ve tipinin ortaya konulabildiği, evrensel olarak uygulanabilen pahalı olmayan ve risk taşımayan bir yöntemdir (Zankl ve Molinari, 2003; Cattoni ve Fernandes, 2009). Buna ek olarak bireyin gelișimi ve boyutları yanı sıra tüm yaşlarda bireylerin ve toplumun tümüyle sağlık ve refahını yansitan antropometrik ölçümler, performans, sağlık ve hayatta kalmayı önceden ortaya koymak için kullanılabilir (Şehla, 2006).
Sex Based Comparative Examination of Craniofacial Anthropometric Measurements in Medical School Students Abstract

For many years, the anatomical structure of the buman body, its normal limits and what the standard measures should be have been discussed, and certain norms have been created by examining their relationships with each other. Craniofacial anthropometry is a branch of anthropometry and covers head and face measurements in live, cadaveric and radiological samples. In our study, we aimed to determine the national normal values and to investigate possible differences between genders with cranial and facial anthropometric measurements of Kirssehir Abi Evran University Faculty of Medicine 1st and 2nd grade students. Our study was conducted on a total of 80 medical school students whose ages ranged between 18 and 24, without craniofacial anomalies. Students' Body Mass Index (BMI) was calculated and 19 anthropometric landmarks were determined for the measurements. The variables of maximum head width, cranial base width, maximum head length, maximum face width, nose width, ear length and ear width were found to be statistically significant between girl and boy groups $(p<0.05)$. The variables of minimum frontal width, head height, total craniofacial head height, mandibular width, and nose height were found to be statistically bighly significant between girl and boy groups $(p<0.001)$. BMI values were calculated as 21.4 (19.7-24.0) for girls and 23.5 (22.1-24.9) for boys. As a result of our study, our head and face measurements show significant differences regarding the sex of the individuals.

Key Words: Antbropometry, craniofacial measurements, body mass index, head and face measurements

Kraniofasiyal antropometri ise antropometrinin bir dalı olup canlı, kadavra ve radyolojik örneklerdeki baş ve yüz ölçümlerini kapsamaktadır (Golalipour, 2006; Umar vd., 2006). Günümüzde kraniyofasiyal antropometrik ölçümler genetik danışmanlığında ve plastik cerrahide önemli bir yer tutmaktadır. Genetik danışmanlığında bu ölçümler, morfolojik bozukluk ile karakterize sendromların olabildiğince doğru açıklanabilmesi için çok gereklidir (Nagle vd., 2005; Malas vd., 2020). Dismorfik karakterler, klinisyenler 
tarafindan bazı açıklayıcı terimler ile tarif edilir ki bunlar "geniş basmakalıp gözler, geniş burun, geniş ağız" gibi terimlerdir. Bu tür açklamalar kişisel olarak tanımlanmış açıklamalardır. Antropometrik ölçümler bu kişisel tanımlamalardan doğabilecek problemlerin giderilmesinde belli bir standart oluşturulmasina yardımcı olabilir (Nagle vd., 2005). Kalıtsal kraniyofasiyal dismorfolojilerin veya travma sonrası bozuklukların uygun cerrahi prosedür ile düzeltilmesini seçmek, popülasyonun normal verileri hakkında bilgi gerektirir (Farkas vd., 2007).

Birçok çalışma göstermiştir ki; farklı doğrusal ve açısal kraniyofasiyal ölçümler kız ve erkeklerde farklılık göstermektedir. Ayrıca ölçümler yaş ve farklı insan topluluklarına bağlı olarak da değişmektedir. Farklı populasyonlar için cinsiyet ve yaş grupları açısından kraniyofasiyal ölçüm standartlarının oluşması gerekmektedir. Elde edilen standartlar da hastalıkların teşhisinde ve tedavi planlamasında kullanılmalıdır (Johannsdottir vd., 1999; Thordarson vd., 2006).

Kraniyofasiyal bölgeden alınan antropometrik ölçümlerin değerlendirilebilmesi için kullanılan yöntemlerin hepsi kraniyofasiyal görünüş ile ilgili işaretleri oluşturur. Baş ve yüzden alınan her veri çok önemlidir fakat tek başlarına bir şey ifade etmezler. Her biri tam yapının tuğlaları gibidir. Bütün içerisinde hepsi bir ahenk oluşturur. Tüm ölçümler birlikte değerlendirilirse en güzel sonucu verir (Özdemir vd., 2007).

Biz de çalışmamızda Kırşehir Ahi Evran Üniversitesi Tıp Fakültesi 1 ve 2. sınıf öğrencilerinin kraniyal ve fasiyal bölgesinde yapılan antropometrik ölçümler ile ülkedeki normal değerleri belirlenmesine katkı sunabilecek bir veri seti sunmayı ve cinsiyetler arasındaki olası farklılıkları araştırmayı amaçladık.

\section{Gereç ve Yöntem}

Çalışmamız yaşları 18 ile 24 arasında değişmekte olan toplam 80 tıp fakültesi öğrencisi üzerinde yapılmıştır. Öğrencilerin 40 tanesi k1z, 40 tanesi erkektir. Araştırma için Kırşehir Ahi Evran Üniversitesi Tip Fakültesi Girişimsel Olmayan Klinik Araştırmalar Etik Kurulu'ndan onay alındı (Karar No: 2018-04/42). Çalışmaya herhangi bir kraniofasiyal anomalisi olmayan, kraniofasiyal travma veya operasyon geçirmemiş bireyler dâhil edilmiştir. Gönüllülere ölçümler hakkında bilgi verilmiş ve bilgilendirilmiş onam formu imzalatılmıştır.

Ölçümler doğrudan denek üzerinde yumuşak ve esnemeyen mezura, Holtain antropometrik set ve dijital kumpas kullanılarak yapılmıştır. Vertex ile ilgili ölçümler alınırken şahıs, başın standart pozisyonu olan Frankfurt Horizontal Planı'na getirilmiştir. Çalışmamızda direkt antropometrik ölçüm teknikleri kullanılarak baş ve yüz bölgesinden, tek bir araştırmacı tarafindan Tablo

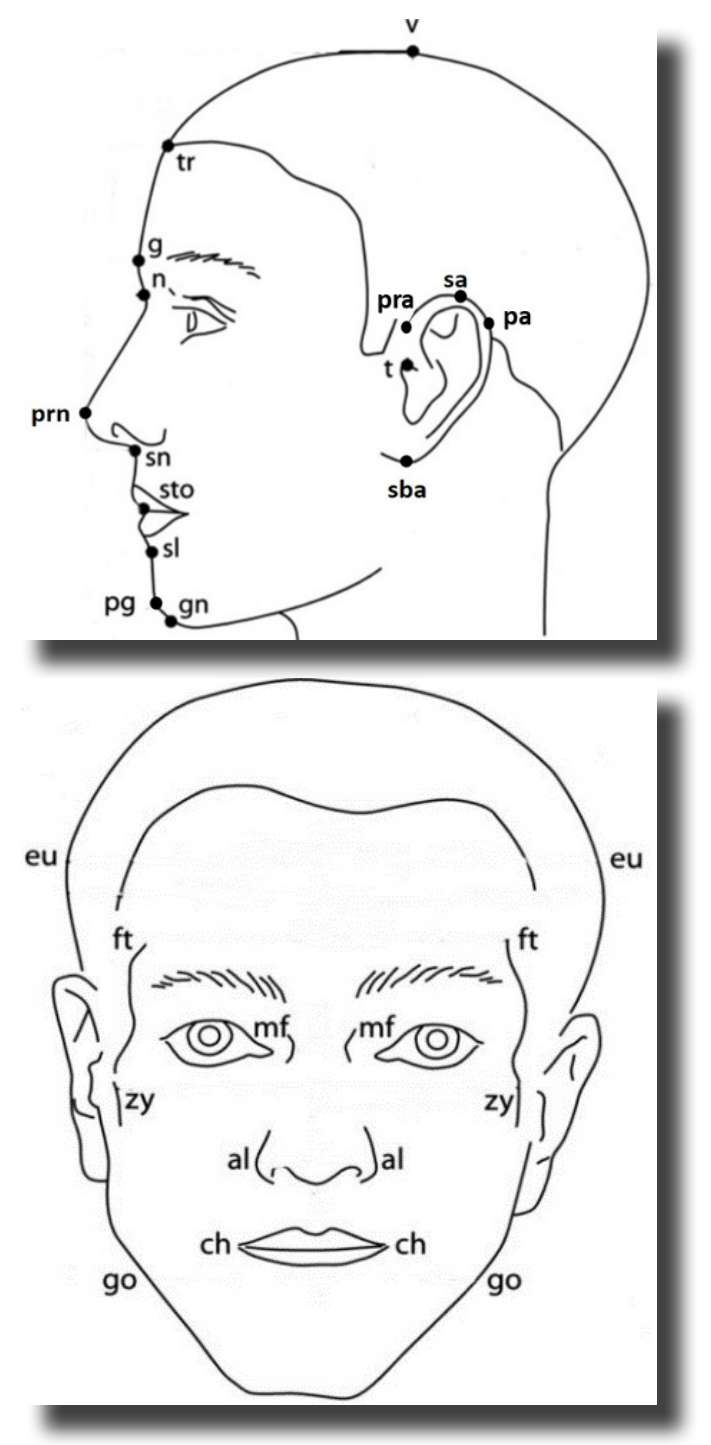

Resim 1. (üstte) Baş ve kulak ile ilgili antropometrik noktalar. (altta) Yüz ile ilgili antropometrik noktalar.

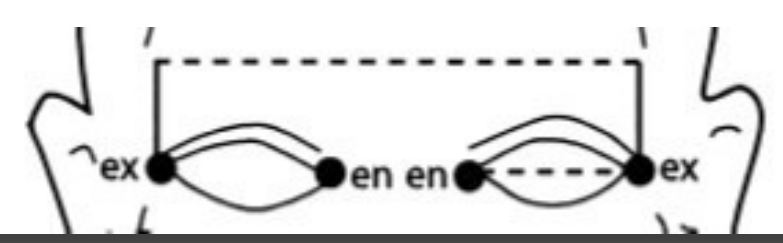

Resim 2. Orbita ile ilgili antropometrik noktalar (Farks vd., 2005).

1'de belirtilen ölçümler üçer defa alınarak ortalamaları hesaplanmıştır. Alınan 19 ölçüm için 19 antropometrik nokta belirlenerek kullanılmıştır (Resim 1, 2):

1. Euryon (eu): Kafatasının her iki yan tarafi üzerinde parietal ve temporal kemik alanlarda lateralde yer alan en çıkıntılı noktadır (Farkas, 1994; Ögetürk, 1998).

2. Frontotemporale (ft): Linea temporalis'in yükseldiği kısmın üzerinde ve alnın her iki yan tarafinda yer alan noktadır (Farkas, 1994; Ögetürk, 1998).

3. Glabella (g): Kaşlar arasındaki en çıkıntılı noktadır (Farkas, 1994; Ögetürk, 1998). 

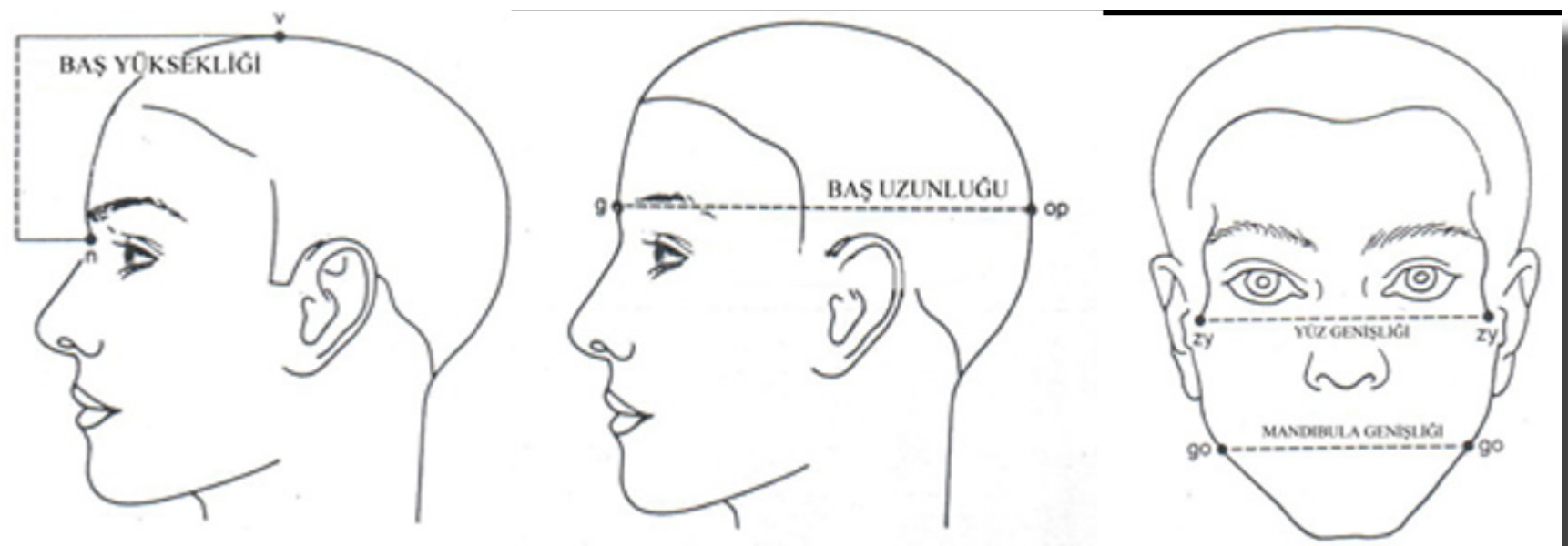

Resim 3. Baş ve yüze ait antropometrik ölçümler (Farkas vd., 1992b’den düzenlenmiştir).

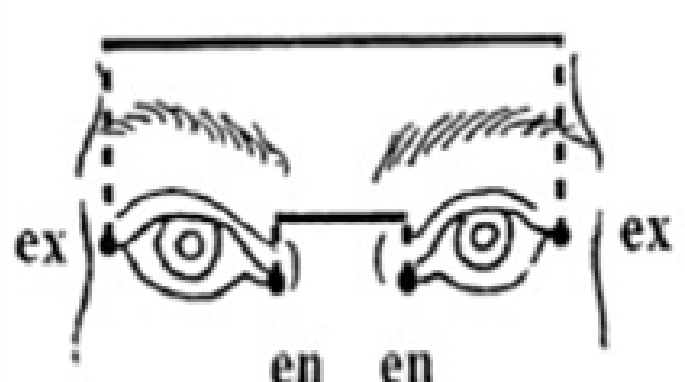

en en

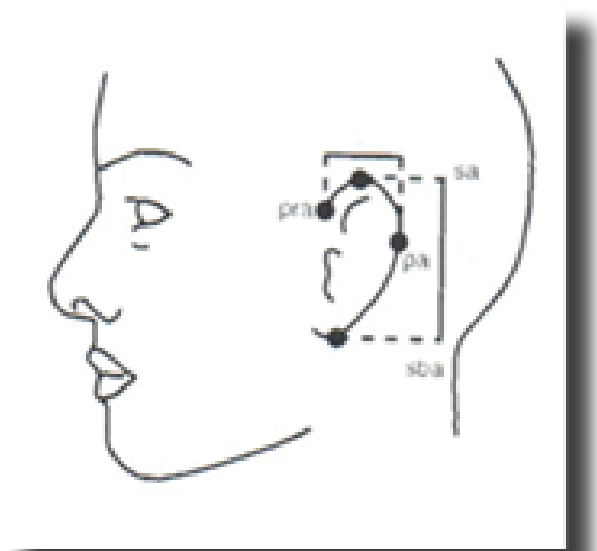

Resim 4. (Sol üst) Göz, (sağ üst) burun ve (alt) kulağa ait antropometrik ölçümler (Farkas vd., 2001; Farkas vd., 2002'den düzenlenmiştir)
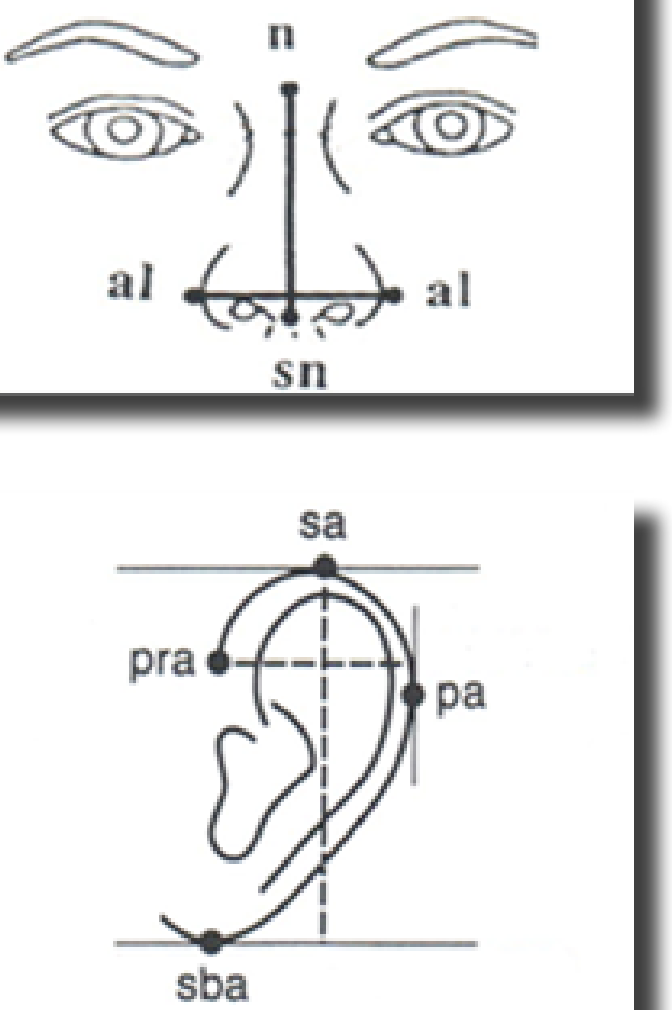

noktasıdır (Farkas, 1994; Ögetürk, 1998).

4. Opisthorcranion (op): Başın occipital bölgesinde yer alan ve glabella'dan en uzak mesafedeki noktadır (Farkas, 1994; Ögetürk, 1998).

5. Vertex (v): Standart pozisyondaki başın en yüksek noktasıdır (Farkas, 1994; Ögetürk, 1998).

6. Gnathion (gn): Mandibula alt kenarı üzerindeki en alt orta noktadır (Farkas, 1994; Ögetürk, 1998).

7. Gonion (go): Angulus mandibula'nin en lateral
8. Zygion (zy): Her iki taraftaki zygomatik arkların en lateraldeki noktasıdır (Farkas, 1994; Ögetürk, 1998).

9. Endocanthion (en): Göz kapaklarının medialde birleştiği noktadır (Farkas, 1994; Ögetürk, 1998).

10. Exocanthion (ex): Göz kapaklarının lateralde birleştiği noktadır (Farkas, 1994; Ögetürk, 1998).

11. Alare (al): Burun kanadının en lateral noktasıdır 
Ulcay ve Kamaşak|Antropoloji (39) (2020)

Tablo 1. Kraniyofasiyal antropometrik ölçümler.

\begin{tabular}{|c|c|c|}
\hline Ölçüm İsimleri & Antropometrik Noktalar & Kisaltmalar \\
\hline Maksimum baş genişliği & Euryon- Euryon & eu-eu \\
\hline Minimum frontal genişlik & Frontotemp.-Frontotemp. & $\mathrm{ft}-\mathrm{ft}$ \\
\hline Kraniyal taban genişliği & Tragion- Tragion & $t-t$ \\
\hline Maksimum baş uzunluğu & Glabella-Opistocranion & g-op \\
\hline Baş yüksekliği & Vertex- Nasion & $\mathrm{v}-\mathrm{n}$ \\
\hline Total kraniyofasial baş yüksekliği & Vertex- Gnation & $v-g n$ \\
\hline Maksimum yüz genişliği & Zygion- Zygion & $z y-z y$ \\
\hline Mandibular genişlik & Gonion- Gonion & go-go \\
\hline İç kantal mesafe & Endocanthion- Endocanthion & en-en \\
\hline Bioküler genişlik(dış kantal mesafe) & Exocanthion- Exocanthion & ex-ex \\
\hline Göz fissür uzunluğu & Endocant.- Exocant. & en- ex \\
\hline Burun genişliği & Alare- Alare & al-al \\
\hline Burun yüksekliği & Nasion- Subnasale & n-sn \\
\hline Labial fissür genişliği & Cheilion- Cheilion & ch-ch \\
\hline Kulak uzunluğu & Superaurale-subaurale & Sa-sba \\
\hline Kulak genişliği & Praeaurale-postaurale & Pra-pa \\
\hline
\end{tabular}

(Farkas, 1994; Ögetürk, 1998).

12. Nasion (n): Sutura nasofrontalis'in orta hat ile kesiştiği noktadır (Farkas, 1994; Ögetürk, 1998).

13. Subnasale (sn): Septum nasale'nin alt kenar1 ile üst dudak yüzeyinin birleştiği columella tabanındaki açının orta noktasıdır (Farkas, 1994; Ögetürk, 1998).

14. Cheilion (ch): Her iki commissura labiorum'larda yer alan noktadır (Farkas, 1994; Ögetürk, 1998).

15. Postaurale (pa): Kulağın serbest kenarı üzerinde en arka noktadır (Farkas, 1994; Ögetürk, 1998).

16. Preaurale (pra): Kulağın en ön noktası olup helix'in başa bağlandiğ1 yerin tam önünde bulunur (Farkas, 1994; Ögetürk, 1998).

17. Superaurale (sa): Kulağın serbest kenarı üzerinde en yüksek noktadır (Farkas, 1994; Ögetürk, 1998).

18. Subaurale (sba): Kulak memesi serbest kenar1 üzerindeki en alt noktadır (Farkas, 1994; Ögetürk, 1998).

19. Tragion ( $\mathrm{t}$ ): Tragus'un üst kenar1 üzerindeki çentiktir (Farkas, 1994; Ögetürk, 1998).

\section{Istatistiksel analiz}

Verilerin normal dağıllıma uygunluğu Histogram, Q-Q grafikleri ve Shapiro-wilk testi ile değerlendirilmiştir. Varyans homojenliği Levene testi ile test edilmiştir. İkili gruplar arası karşılaştırmalarda nicel değişkenler için Mann-Whitney U testi ve bağımsız iki örneklem t-testi uygulanmıştır. Verilerin analizi SPSS 22.0 paket programı kullanılarak gerçekleştirilmiştir. Anlamlılık düzeyi $\mathrm{p}<0,05$ olarak kabul edilmiştir.

\section{Bulgular}

Örneklem grubunu oluşturan 40 k1z ve 40 erkek öğrencinin yaş ortalaması 19,48 \pm 1,41 olarak bulunmuştur. Kızlar ve erkeklerin vücut kütle indeksi (BMI) hesaplanmıştır ve gruplar arasında BMI değeri istatistiksel olarak anlamlı bulunmuştur $(p=0,01)$. Erkeklerin BMI dağılımı, kızlardan daha yüksek bulunmuştur (Tablo 2).

Normal dağılım gösteren baş, yüz ve kulak ile ilgili antropometrik ölçümlerden; maksimum baş genişliği, kraniyal taban genişliği, maksimum baş uzunluğu, maksimum yüz genişliği, burun genişliği, kulak uzunluğu ve kulak genişliği değişkenleri kız ve erkek grupları arasinda istatistiksel olarak anlamlı fark bulunmuştur $(p<0,05)$. Erkeklerdeki ortalama maksimum baş genişliği, kraniyal taban genişliği, 
Tablo 2. Kraniyofasiyal antropometrik ölçüm sonuçları

\begin{tabular}{|c|c|c|c|}
\hline \multirow[b]{2}{*}{ Değişkenler } & \multicolumn{2}{|c|}{ Gruplar } & \multirow[b]{2}{*}{$p$} \\
\hline & $K_{1 z}(n=40)$ & Erkek $(n=40)$ & \\
\hline BMI & $21,4(19,7-24,0)$ & $23,5(22,1-24,9)$ & 0,01 \\
\hline eu-eu & $136,80 \pm 9,25$ & $148,64 \pm 8,03$ & $<0,001$ \\
\hline $\mathrm{ft}-\mathrm{ft}$ & $107,2(93,4-121)$ & $118,4(101,2-143)$ & $<0,001$ \\
\hline$t-\mathrm{t}$ & $129,65 \pm 8,17$ & $138,85 \pm 5,82$ & $<0,001$ \\
\hline g-op & $173,63 \pm 5,71$ & $188,40 \pm 7,67$ & $<0,001$ \\
\hline $\mathrm{v}-\mathrm{n}$ & $107,64(102,6-116,8)$ & $124,83(115,6-138,6)$ & $<0,001$ \\
\hline v-gn & $185,7(181,1-191,4)$ & $215,5(196,7-229,4)$ & $<0,001$ \\
\hline$z y-z y$ & $120,28 \pm 9,19$ & $130,89 \pm 9,90$ & 0,001 \\
\hline go-go & $100,0(94,0-106,3)$ & $107,2(100,0-116,2)$ & $<0,001$ \\
\hline en-en & $33,5(31,2-34,4)$ & $32,1(30,8-34,7)$ & 0,324 \\
\hline ex-ex & $102,97 \pm 5,44$ & $104,50 \pm 5,29$ & 0,206 \\
\hline en-ex sağ & $37,3(35,2-40,5)$ & $37,2(35,2-41,0)$ & 0,908 \\
\hline en-ex sol & $37,70 \pm 3,31$ & $38,44 \pm 3,53$ & 0,338 \\
\hline al-al & $32,67 \pm 2,98$ & $35,03 \pm 2,87$ & 0,001 \\
\hline n-sn & $52,4(49,4-55,4)$ & $60,2(51,9-64,5)$ & $<0,001$ \\
\hline ch-ch & $50,89 \pm 3,84$ & $50,44 \pm 4,56$ & 0,634 \\
\hline sa-sba sağ & $59,93 \pm 4,18$ & $62,22 \pm 4,21$ & 0,017 \\
\hline sa-sba sol & $59,77 \pm 4,25$ & $62,46 \pm 4,11$ & 0,005 \\
\hline pra-pa sağ & $38,49 \pm 2,91$ & $36,83 \pm 4,33$ & 0,048 \\
\hline pra-pa sol & $38,32 \pm 2,93$ & $36,47 \pm 4,57$ & 0,035 \\
\hline
\end{tabular}

maksimum baş uzunluğu, maksimum yüz genişliği, burun genişliği, kulak uzunluğu ölçüm değerleri, kızlara göre daha yüksek bulunmasına rağmen, kulak genişliği ölçüm değerleri, kızlara göre daha düşük bulunmuştur. Dış kantal mesafe, sol göz fissür uzunluğu ve labial fissür genişliği değişkenleri için kızlar ve erkekler arasında istatistiksel olarak anlamlı bir fark bulunmamıştır (Tablo 2).

Normal dağılım göstermeyen baş ve yüz ile ilgili antropometrik ölçümlerden; minimum frontal genişlik, baş yüksekliği, total kraniofasiyal baş yüksekliği, mandibular genişlik ve burun yüksekliği değişkenleri kız ve erkek grupları arasında istatistiksel olarak yüksek derecede anlamlı fark bulunmuştur $(p<0,001)$ (Resim 5). Bu ölçümlerin değerleri kızlara göre erkeklerde daha yüksek bulunmuştur. Kız ve erkek grupları arasında orbital antropometrik ölçümlerden iç kantal mesafe ve sağ göz fissür uzunluğu değişkenleri için istatistiksel anlamlılık bulunmamıștır. Kızlarda bu ölçümlerin değerleri erkeklere göre daha yüksek bulunmuştur (Tablo 2).

\section{Tartışma}

İnsan vücudunun anatomik yap1s1, normal sınırlar1 ve bunlarla ilgili standart ölçülerin ne olması gerektiği yüzyıllardan beri tartışılmış ve birbirleriyle olan ilişkileri incelenerek belirli normlar oluşturulmuştur. Antropometrik çalışmalar sonucu oluşan bu normlarin kraniyofasiyal cerrahi, otorinolaringoloji ve sendromolojide yararlı olduğu kabul edilmektedir. Baş ve yüz bölgesi üzerinde yapılan antropometrik çalş̧malardan elde edilen bilgiler, bu bölgedeki şekil bozukluklarına sahip hastaların plastik cerrahi sürecinin hesaplanmasinda kullanilabilir (Farkas vd., 1992a).

Baş genişliği kafatasının en lateral noktaları arasindaki mesafe olup her iki cinsiyette de doğumdan sonraki ilk 1 yılda yetişkin boyutunun yaklaşı \% $\%$ 'üne ulaşabilmektedir. Bu oran ilk 5 yıl sonunda yaklaşık 


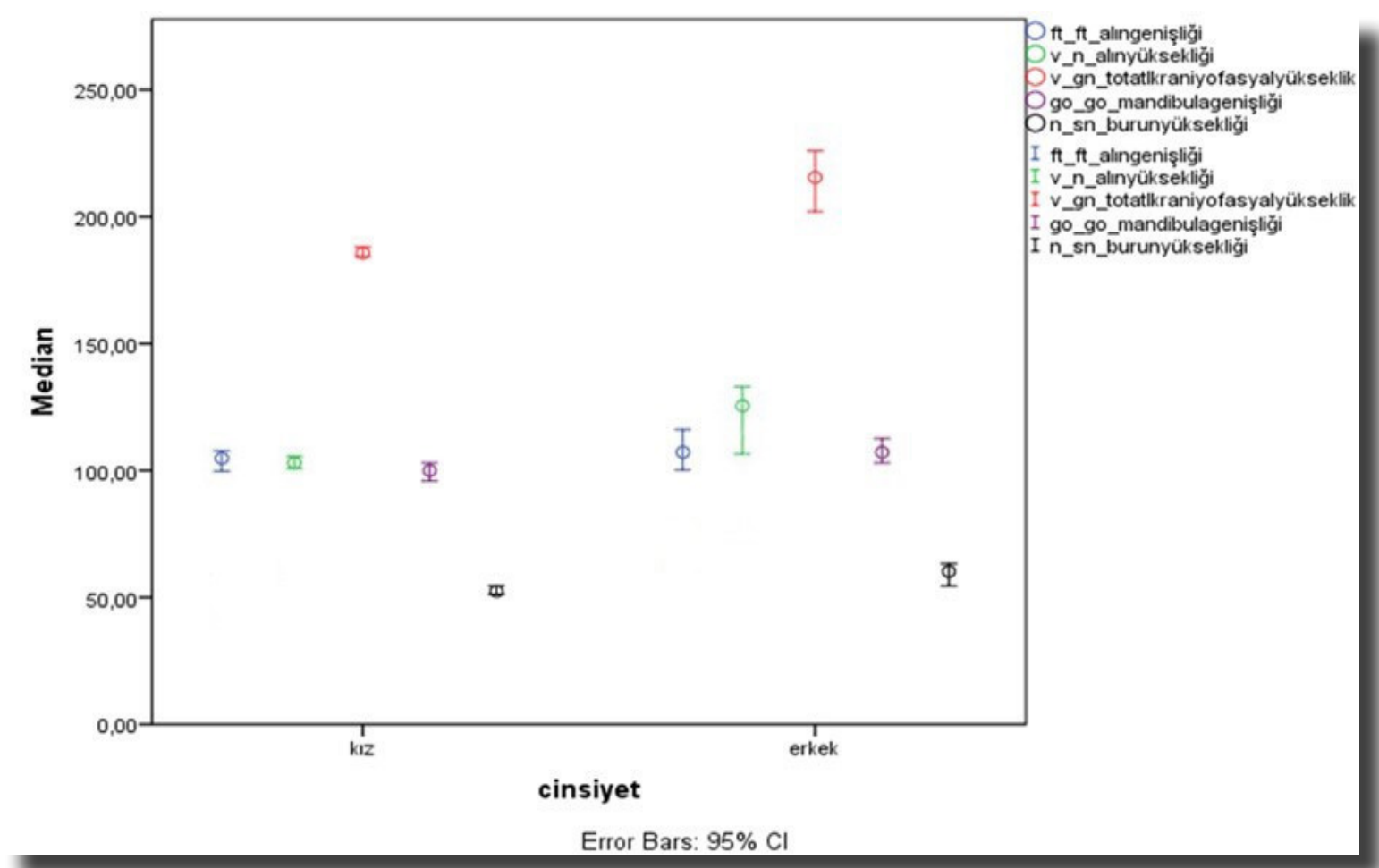

Resim 5. Baş ve yüz ile ilgili antropometrik ölçümlerin Error-Bar grafiği.

\%93’e kadar çıkabilmektedir. Baş genişliği yetisskindeki boyutuna kızlarda 14, erkeklerde ise yaklaşık 15 yaş civarında ulaşmaktadır (Farkas vd., 1992a). Nagle ve ekibi (2005), 18-23 yaş arası bireylerde yaptıkları çalışmada baş genişliğini (eu-eu) erkeklerde 153,2 \pm 10,6 $\mathrm{mm}$, kızlarda ise $146,0 \pm 5,8 \mathrm{~mm}$ olarak ölçmüşlerdir (Nagle vd., 2005). Ngeow ve Aljunid ise, aynı ölçümü 18-25 yaş arası bireylerde yaptıkları çalışmada erkeklerde $155,0 \pm 5,9 \mathrm{~mm}$, kizlarda ise 149,4 $\pm 5,7 \mathrm{~mm}$ olarak bulmuşlardır (Ngeow ve Aljunid, 2009). Farkas ve ekibi (2007), 18-25 yaş arası sağlıklı bireyler üzerinde yaptığ çalışmada baş genişliğini, Afrikan-Amerikan ve Kuzey Amerikan beyaz erkeklerde sirasiyla 148,0 \pm 9,5 $\mathrm{mm}$ ve $151,1 \pm 5,7 \mathrm{~mm}$; kizlarda ise $141,4 \pm 6,0 \mathrm{~mm}$ ve $144,1 \pm 5,1 \mathrm{~mm}$ olarak bulmuşlardır (Farkas vd., 2007). Çalışmamızda ise baş genişliği açısından erkekler literatürle benzerlik gösterirken $(148,64 \pm 8,03 \mathrm{~mm})$, kızlar daha düşük değerlere sahipti (136,80 \pm 9,25 mm).

Minimum frontal genişlik (ft-ft), yetişkin boyutuna kızlarda yaklaşık olarak 13, erkeklerde ise 15 yaşında ulaşmaktadır (Farkas vd., 1992a). Çalışmamızda elde edilen minimum frontal genişlik ölçümleri, literatürdeki benzer çalışmalarla benzerlik göstermektedir (Farkas vd., 2007; Nagle vd., 2005). Ayrica erkeklerin minimum frontal genişlik ölçümleri kızlardan anlamlı derecede yüksek bulunmuştur. Kraniyal taban genişliği (t-t) ise cinsiyete bağlı olarak farklılık göstermekle birlikte literatürle karşılaştırıldığında daha düşük değerler olarak göze çarpmaktaydi. Nagle ve ekibi (2005) kraniyal taban genişliği değerlerini erkeklerde 144,2 $\pm 5,9 \mathrm{~mm}$, kızlarda ise 135,5 \pm 5,0 mm olarak bildirmişlerdir.
Baş uzunluğu, glabella noktası ile kraniyumun en arka noktası olan opisthacranion noktası arası masafe olup doğumdan sonra ilk 1 yılda yetişkin boyutunun yaklaşı \% \%87'sine çıkabilmektedir. Baş uzunluğu kızlarda erkeklere göre daha kısa sürede yetişkin boyutuna ulaşmaktadır. Kızlarda bu yaş 10 iken erkeklerde yaklaşık 14'tür (Farkas vd., 1992a). Çalışmamıza katılan erkeklerde baş uzunluğu (g-op), kızlardan anlamlı derecede yüksek olarak bulunmuştur ve literatürle karşılaştırıldığında Afro-Amerikalı (Farkas vd., 2007), Kuzey Amerikalı beyazlar (Farkas vd., 2007), Litvanyalı (Nagle vd., 2005) ve Malezyalı (Ngeow ve Aljunid, 2009) aynı yaş grubundaki bireyler ile benzerlik gösterdiği bulunmuştur.

Başın en yüksek noktası olan vertex noktası ile burun kökündeki nasion noktası arası mesafe baş yüksekliğini (v-n) oluşturur. Kuzlarda ve erkeklerde yaklaşık olarak 13 yaş civarında yetişkindeki boyutuna ulaşmaktadır (Farkas vd., 1992a). Çalışmamızda elde edilen baş yüksekliği verileri Farkas ve arkadaşlarının (2007) verileriyle tamamen uyumluydu. Ngeow ve Aljunid ise Malezyalı aynı yaş grubundaki bireylerde baş yüksekliği açısından çok düşük değerler bildirmişlerdir (Erkekler: 104,4 \pm 8,4 mm, kzzlar: 94,8 \pm 6,5 mm) (Ngeow ve Aljunid, 2009). Bu değerlerin farkliliğ1 ölçüm hatasından kaynaklanabileceği gibi biyolojik ve kültürel farkl1liklardan kaynaklanan varyasyon sonucu da oluşabilmektedir.

Yüzdeki horizontal ölçümlerden biri olan maksimum yüz genişliği (bizigomatik çap, üst yüz genişliği), sağ ve sol zigomatik arkların en lateral 
noktaları arası mesafe (zy-zy) olarak tanımlanmaktadır. Maksimum yüz genişliği erkeklerde 15 yaşında, kızlarda ise 13 yaşında tamamen gelişimini tamamlamaktadır (Farkas vd., 1992b). Çalışmamızda elde edilen yüz genişliği verileri, Farkas ve ekibinin (2007) verileri ile kıyaslandığında daha düşük olduğu görülmektedir. Nagle ve ekibinin (2005) bildirdiği veriler ile tamamen uyuşmaktadır. Bu çalışmaların aksine Ngeow ve Aljunid, kızlarda yüz genişliğini erkeklerden anlamlı derecede yüksek bulmuştur (Erkekler: 132,5 $\pm 7,0 \mathrm{~mm}$, kızlar: 140,1 \pm 4,9 mm) (Ngeow ve Aljunid, 2009).

Yüz bölgesinin horizontal ölçümlerinden birisi olan mandibula genişliği (bigonion çap, alt yüz genişliği) mandibula'nın her iki tarafındaki gonion noktaları arası mesafedir. Doğumdan sonraki ilk 1 yılda mandibula genişliği yetişkindeki boyutunun \%80'ine ulaşabilmektedir. Bu oran 5 y1l sonunda \%92'ye kadar çıkabilmektedir. Mandibula genişliği tam gelişimini yaklaşık olarak erkeklerde 13, kızlarda ise 12 yaş civarında tamamlamaktadır (Farkas vd., 1992b). Malas ve ekibi (2020), yaşları 17-35 arasında değişen 25 erkek ve 25 kadın toplam 50 kişi üzerinde yaptıkları çalışmada mandibula genişliğini erkeklerde 112,0 $\pm 5,0 \mathrm{~mm}$, kızlarda ise 107,0 $\pm 9,0$ mm olarak ölçmüşlerdir (Malas vd., 2020). Nagle ve ekibi ise aynı ölçümü erkeklerde 105,4 \pm 6,3mm, kızlarda ise 96,9 \pm 7,5 mm olarak bulmuşlardır (Nagle vd., 2005). Farkas ve ekibi de mandibular genişliği Nagle ve ekinine (Nagle vd., 2005) uyumlu olarak bildirmişlerdir (Farkas vd., 2007). Çalışmamızdaki veriler, erkeklerin anlamlı derecede kızlardan geniş mandibula'ya sahip olduğunu göstermektedir.

Orbita bölgesindeki iç kantal mesafe ve bioküler genişlik yüzün harmonisi açısından önemli verileri oluşturur. İç kantal mesafe yetişkindeki boyutunu kızlarda yaklaşık 8, erkeklerde ise 11 yaş civarında alırken, bioküler genişlik ise gelişimini yaklaşık olarak erkeklerde 15, kızlarda ise 13 yaşında tamamlamaktadır (Farkas vd., 1992a). Charles ve ekibinin (2008) Nijerya'da yaşları 22-40 arasında değişen bireylerde yaptıkları çalışmada iç kantal mesafeyi erkeklerde 42,3 $\pm 4,9 \mathrm{~mm}$, kızlarda ise 39,0 $\pm 3,1 \mathrm{~mm}$; bioküler genişliği ise erkeklerde $110,9 \pm 13,7 \mathrm{~mm}$, kizlarda ise 119,6 \pm 7,0 mm olarak bildirmişlerdir (Charles vd., 2008). Bu veriler çalışmamızdaki verilerden ve literatürdeki aynı yaş grubunda yapilan çalışmalardaki (Johannsdottir vd., 1999; Farkas vd., 2007; Ngeow ve Aljunid, 2009) verilerden yüksek olduğu göze çarpmaktadır. Ayrıca çalışmamızda kız ve erkekler arasında iç kantal mesafe ve bioküler genişlik açısından anlamlı farklılı̆̆ın olmaması açısından da literatürle uyumluydu. Çalışmamızda, hem sağ tarafta hem de sol tarafta göz fissür uzunluğu verilerinin literatürdeki diğer verilerden daha yüksek olması dikkat çekmektedir. Yani göz fissür uzunluğu verilerimiz her iki taraf içinde hem kızlarda hem de erkeklerde Litvanyalı (Nagle vd., 2005), Amerikalı (Farkas vd., 2007) ve Malezyalı (Ngeow ve Aljunid, 2009) bireylerden daha yüksek değerlere sahipti.

Burun yüksekliği (n-sn) ve burun genişliği (alal), antropometride burun ile ilgili ölçümlerin en önemlileridir. Burun yüksekliği gelişimini erkeklerde 15 , kızlarda ise 12 yaş civarında tamamlayabilmektedir. Burun genişliği erkeklerde 14, kızlarda ise 12 yaş civarında yetişkindeki boyutuna ulaşmaktadır (Farkas vd., 1992b). Çalışmamızda elde ettiğimiz burun ölçümlerine ait veriler Nagle'nin (Nagle vd., 2005) ve Farkas'in (Farkas vd., 2007) bildirdiği veriler ile tamamen uyuşmaktadır. Ngeow ve Aljunid ise burun genişliği açısından daha yüksek veriler bildirmiştir (Ngeow ve Aljunid, 2009). Malezyalı ve Afro-Amerikalıların burun genişliği verilerinin çalışmamızdaki verilerden yüksek olduğu göze çarpmaktadır. Ayrıca çalışmamızdaki buruna ait veriler erkeklerde kızlara oranla anlamlı derecede yüksektir. Bu açıdan da literatürle uyumludur.

Kulak uzunluğu (sa-sba) ve kulak genişliği (pra-pa) puberteye kadar yetişkindeki boyutuna ulaşmaktadır. Çalısmamızda elde ettiğimiz kulak ile ilgili veriler literatürde yapılan aynı yaş grubundaki çalışmalardaki veriler ile uyumludur (Farkas vd., 2001; Farkas vd., 2005; Farkas vd., 2007). Yine literatürle uyumlu olarak kulağa ait verilerimizde cinsiyete bağlı anlamlı bir farklılık bulunmamaktadır.

\section{Sonuç}

Çalışmamızın sonucunda baş ve yüze ait verilerimizin geneli cinsiyete bağlı olarak anlamlı farklilıklar göstermekte ve erkeklerin ölçümlerinin kızlardan anlamlı derecede yüksek olduğu görülmektedir. Aynı zamanda farklı uluslara ait verilerle karşılaştırma yapılması toplumumuzun yapisal kraniofasiyal özelliklerinin belirlenmesi açısından önemli olacağı kanaatindeyiz. Birçok çalışma göstermiştir ki; farklı doğrusal kraniyofasiyal ölçümler kız ve erkeklerde farklılık göstermektedir. Ayrıca ölçümler yaşa bağlı olarak da değişmektedir. Farklı popülasyonlar için cinsiyet ve yaş grupları açısından kraniyofasiyal ölçüm standartlarının oluşmas1 gerekmektedir. Elde edilen standartlar da hastalıkların teşhisinde ve tedavi planlamasında kullanılmalıdır.

\section{Kaynakça}

Cattoni, D. M., ve Fernandes, F. (2009). Anthropometric orofacial measurements of children from Sao Paulo and from North America: comparative study. Pro-fono: revista de atualizacao cientifica, 21(1), 25-29. http://doi.org/10.1590/S0104$\underline{56872009000100005}$

Charles, O., Hakeem, F., Nerwey, D., ve Mildred, B. (2008). Normal Outer and Inner Canthal Measurements of Ijaws of Southern Nigeria. European Journal of Scientific Research, 22, 163-167. 
Farkas, L. G., Posnick, J. C., ve Hreczko, T. M. (1992a). Anthropometric growth study of the head. The Cleft Palate-Craniofacial Journal, 29(4), 303-308. https://doi. org/10.1597/1545-1569 19920290303 agsoth 2.3.co 2

Farkas, L. G., Posnick, J. C., ve Hreczko, T. M. (1992b). Growth patterns of the face: a morphometric study. The Cleft Palate-Craniofacial Journal, 29(4), 308-314. https://doi. org/10.1597/1545-1569 19920290308 gpotfa 2.3.co 2

Farkas, L. G. (1994). Examination. L. G. Farkas (Ed.) içinde, Anthropometry of the head and face (s. 3-56). Raven Press.

Farkas, L. G., Posnick, J. C., Hreczko, T. M., ve Pron, G. E. (1992). Growth patterns in the orbital region: a morphometric study. The Cleft Palate-Craniofacial Journal, 29(4), 315-318. https://doi. org/10.1597/1545-1569 19920290315 gpitor 2.3.co 2

Farkas, L. G., Posnick, J. C., Hreczko, T. M., ve Pron, G. E. (1992). Growth patterns of the nasolabial region: a morphometric study. The Cleft Palate-Craniofacial Journal, 29(4), 318-324. https://doi.org/10.1597/1545-1569 $1992 \quad 0290318$ gpotnr 2.3.co 2

Farkas, L. G., Katic, M. J., ve Forrest, C. R. (2002). Agerelated changes in anthropometric measurements in the craniofacial regions and in height in Down's syndrome. The Journal of Craniofacial Surgery, 13(5), 614-622. https://doi. org/10.1097/00001665-200209000-00004

Farkas, L. G., Katic, M. J., ve Forrest, C. R. (2007). Comparison of craniofacial measurements of young adult African-American and North American white males and females. Annals of Plastic Surgery, 59(6), 692-698. https://doi.org/10.1097/01. sap.0000258954.55068.b4

Farkas, L. G., Katic, M. J., Forrest, C. R. (2005). International anthropometric study of facial morphology in various ethnic groups/races. The Journal of Craniofacial Surgery, 16(4), 615-646. https://doi.org/10.1097/01.scs.0000171847.58031.9e

Farkas, L. G., Katic, M. J., Forrest, C. R., ve Litsas, L. (2001). Surface anatomy of the face in Down's syndrome: linear and angular measurements in the craniofacial regions. The Journal of Craniofacial Surgery, 12(4), 373-379; discussion 380. https:// doi.org/10.1097/00001665-200107000-00011

Golalipour, M. J. (2006). The effect of ethnic factor on cephalic index in 17-20 years old females of north of Iran. International Journal of Morphology, 24(3), 319-322. https://doi.org/10.4067/ $\underline{\mathrm{S} 0717-95022006000400004}$

Johannsdottir, B., Thordarson, A., ve Magnusson, T. E. (1999). Craniofacial morphology in 6-year-old Icelandic children. European Journal of Orthodontics, 21(3), 283-290. https://doi. org/10.1093/ejo/21.3.283

Malas, M. A., Sulak, O., Aler, A., ve Öktem, F. (1998). Prematüre yenidoğanlarda kranyofasiyal morfoloji. SDÜ T⿰р Fakültesi Dergisi, 5(1), 25-31.

Nagle, E., Teibe, U., ve Kažoka, D. (2005). Craniofacial anthropometry in a group of healthy Latvian residents. Acta Medica Lituanica, 12, 47-53.

Ngeow, W. C., ve Aljunid, S. (2009). Craniofacial anthropometric norms of Malays. Singapore Medical Journal, 50, 525-528.
Ögetürk, M. (1998). Şizofrenik hastalarda bas ve yüz antropometrik ölçümleri. Yayımlanmamış Doktora Tezi. Fırat Üniversitesi, Elazığ.

Özdemir, M. B., Ilgaz, A., Dilek, A., Ayten, H., ve Esat, A. (2007). Describing normal variations of head and face by using standard measurement and craniofacial variability index (CVI) in seven-year-old normal children. The Journal of Craniofacial Surgery, 18(3), 470-474. https://doi.org/10.1097/01. scs.0000265717.53414.3f

Şehla, İ. (2006). 9-72 aylik cocuklarda antropometrik ölçümler ve antropometrik ölçümlere etki eden parametrelerin arastmilmasi. Uzmanlık Tezi, T. C. Sağlık Bakanlığı Bakırköy Dr. Sadi Konuk Eğitim ve Araştırma Hastanesi, İstanbul.

Thordarson, A., Johannsdottir, B., ve Magnusson, T. E. (2006). Craniofacial changes in Icelandic children between 6 and 16 years of age - a longitudinal study. European Journal of Orthodontics, 28(2), 152-165. https://doi.org/10.1093/ejo/ cji084

Umar, M., Singh, R., ve Shugaba, A. (2006). Cephalometric Indicies among Nigerians. Journal of Applied Sciences, 6(4), 939-942. https://doi.org/10.3923/jas.2006.939.942

Zankl, A., Molinari, L. (2003). ABase-A tool for the rapid assessment of anthropometric measurements on handheld computers. American Journal of Medical Genetics Part A, 121 A(2), 146-150. https://doi.org/10.1002/ajmg.a.20185

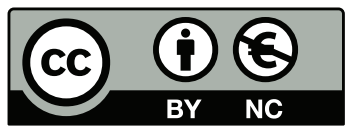

2020. Telif haklar1 yazar(lar)a aittir.

$\mathrm{Bu}$ makale Creative Commons Atıf-GayriTicari 4.0 Uluslararası (CC BY-NC 4.0) lisansının hüküm ve şartları altında yayımlanan açık erişimli bir makaledir. 